Dez 2017 - v.7 - n.2

\title{
Hemoterapia: hemácias fenotipadas para pacientes falcêmicos
}

A hemoterapia é um meio de tratamento da anemia falciforme, sendo as transfusões de concentrado de hemácias fenotipadas mais utilizadas. A anemia falciforme, até os dias de hoje, é um desafio para seus portadores e profissionais da área, porque há uma grande dificuldade dos processos fisiopatológicos e por causa da gravidade de muitas das suas manifestações clínicas. Por isso, é importante que a doença seja detectada precocemente. O profissional biomédico é um dos principais responsável por isso, pois é qualificado para realizar os exames clínicos, a fim de diagnosticar e esclarecer o real quadro clínico e o tratamento adequado para doença. O objetivo do estudo é relatar a importância da hemoterapia em pacientes falcêmicos, dando ênfase à importância dos concentrados de hemácias fenotipadas para os pacientes falcêmicos. A imunofenotipagem eritrocitária nos pacientes portadores de anemia falciforme é importante para prevenir uma das principais complicações da terapia transfusional, uma vez que a presença de aloanticorpos e autoanticorpos dificulta a obtenção de sangue compatível e pode ocasionar reações transfusionais hemolíticas agudas ou tardias, aumentando a morbidade da doença. Deste modo, para o tratamento e diagnóstico correto, existem inúmeros exames, sendo os mais utilizados e qualificados, o teste do pezinho (utiliza-se para um pré-diagnóstico); o hemograma; e a eletroforese de hemoglobina em acetato de celulose ou em agarose, com pH variando de 8 a 9 , que é a técnica mais qualificada para a confirmação do diagnóstico desta hemoglobinopatia.

Palavras-chave: Transfusão sanguínea; Hemácias fenotipadas; Anemia falciforme.

\section{Hemotherapy: phenotype red blood cells for sickle cell patients}

Hemotherapy is a means of treating sickle cell anemia, with the most commonly used phenotype red blood cell transfusions. Sickle cell anemia to this day, is a challenge for its patients and professionals in the field, because there is a great difficulty in pathophysiological processes and because of the severity of many of its clinical manifestations. It is therefore important that the disease is detected early. The biomedical professional is one of the main responsible for this, as it is qualified to perform the clinical exams in order to diagnose and clarify the actual clinical picture and the appropriate treatment for disease. The aim of the study is to report the importance of hemotherapy in sickle cell patients, with emphasis on the importance of phenotyped red blood cell concentrates for sickle cell patients. Erythrocyte immunophenotyping in patients with sickle cell anemia is important in order to prevent one of the main complications of transfusion therapy, since the presence of alloantibodies and autoantibodies leads to the obtaining of compatible blood and can cause acute or late hemolytic transfusion reactions, increasing the morbidity of the disease. Thus, for the treatment and correct diagnosis, there are numerous exams, the most used and qualified being the foot test (used for a pre-diagnosis); the hemogram; and hemoglobin electrophoresis in cellulose acetate or in agarose, with a pH ranging from 8 to 9 , which is the most qualified technique to confirm the diagnosis of this hemoglobinopathy.

Keywords: Blood transfusion; Phenotypic haemocycles; Sickle cell anemia.

\section{Topic: Hematologia e Hemoterapia}

Reviewed anonymously in the process of blind peer

Simone Possas Andrade

Faculdade Guaraí, Brasil

http://lattes.cnpq.br/0552128506796918

simomissag@hotmail.com

\section{Anderson José Gonzaga Lemos}

Universidade Federal do Rio Grande do Sul, Brasil

http://lattes.cnpq.br/0660017521144164

bioander1986@hotmail.com

Mara Soares de Almeida Mota (iD

Faculdade Guaraí, Brasil

http://lattes.cnpq.br/5200758055263996

http://orcid.org/0000-0002-2068-3481

mara.almeida06@gmail.com
Received: 06/12/2017

Approved: 14/12/2017

Patrícia Delmiro de Sousa Takahagassi

Faculdade Guaraí, Brasil

http://lattes.cnpq.br/3931355464582183

patriciarpr@uol.com.br

\section{Referencing this:}

ANDRADE, S. P.; LEMOS, A. J. G.; MOTA, M. S. A.; TAKAHAGASSI, P. D. S.. Hemoterapia: hemácias fenotipadas para pacientes falcêmicos. Scire Salutis, v.7, n.2, p.65-73, 2017. DOI: http://doi.org/10.6008/SPC2236-9600.2017.001.0008 


\section{INTRODUÇÃO}

As transfusões sanguíneas têm grande importância na realização de muitos tratamentos, como os transplantes, quimioterapia, e diversas cirurgias. Mesmo com novos tratamentos, não tem como substituir o sangue humano para fins terapêutico (FERREIRA, 2007). A terapêutica transfusional com concentrado de hemácias é uma prática comum no tratamento e prevenção de complicações na anemia falciforme. Cerca de 50\% dos pacientes portadores de anemia falciforme recebem transfusões de concentrado de hemácias em algum estágio da vida, e de 5\% a 10\% destes entram no programa de transfusão crônica. O principal objetivo da transfusão é melhorar a capacidade de transporte de oxigênio e o fluxo de sangue na microcirculação pela diminuição na porcentagem de Hemoglobina $S(\mathrm{HbS})$ e pelo aumento no nível de hematócrito, que não deverá exceder $30 \%$, o que previne eventos vaso-oclusivos clinicamente significantes.

A hemoterapia consiste na transfusão dos componentes sanguíneos, que são os Concentrados de Hemácias $(\mathrm{CH})$, concentrados de plaquetas, plasmas fresco congelado e crioprecipitado, contudo as mesmas ocorrem dependendo da necessidade do paciente (HELMAN, 2012). As transfusões de hemocomponentes e hemoderivados apresentam riscos e alguns deles fatais. Entre as chamadas reações transfusionais estão as hemolíticas, as complicações pulmonares, o desequilíbrio eletrolítico, as sepses bacterianas, a hipotermia, a doença do enxerto versus hospedeiro, a aloimunização, a sobrecarga de volume, a sobrecarga de ferro e a imunossupressão (FERREIRA, 2007).

Existem vários tipos de anemias que necessitam de transfusão, como a anemia ferropriva, megaloblástica, as anemias hemolíticas, aplástica, perniciosa, e dentre elas, a anemia falciforme, que é uma das doenças falciformes (FERRAZ, 2007). A doença falciforme é um grupo de anemias hemolíticas hereditárias, que são caracterizadas pela presença de hemoglobina S, onde se apresenta em homozigose (Hb SS), chamado de anemia falciforme; em heterozigose, quando aparecem outras hemoglobinas variantes (Hb SC, $\mathrm{Hb}$ SD, etc.), e a interação com as talassêmias ( $H b S / B^{\circ}, \mathrm{Hb} \mathrm{S} / \mathrm{B}+, \mathrm{Hb} / \mathrm{alfa}$ ) (FERRAZ, 2007).

A anemia falciforme se caracteriza por uma alteração no gene ocasionada por uma mutação à substituição de uma base nitrogenada (GAG para GTG) que ocorre no códon que codifica o sexto aminoácido da cadeia, com isso origina-se a valina ao invés do ácido glutâmico na cadeia beta variante, ocorrendo a modificação da estrutura tridimensional da hemoglobina que origina assim hemoglobina $\mathrm{S}(\mathrm{HbS})$ responsável pelo aparecimento destas doenças (MARQUES, 2012).

Portanto, a transfusão de concentrado de hemácias é de grande importância para os doentes falcêmicos, pois melhora a sobrevida dos doentes e evita complicações causadas pela anemia falciforme. A terapia transfusional, tem por objetivo melhorar uma condição grave e evitar algumas das principais complicações crônicas da doença, como a vaso oclusão e a síndrome mão-pé. Mas o principal objetivo é aumentar a concentração de hemácias, por conseguinte o hematócrito (Hto) e desta forma, aumentar a oxigenação sanguínea, diminuindo a hipóxia tecidual, consequentemente diminuindo a produção de HbS (PINTO, 2001). 
Desta forma, os pacientes falcêmicos quando transfundidos, recebem hemácias fenotipadas que evita que os pacientes sejam aloimunizados. Os hemocomponentes fenotipados reduzem os casos de aloimunização e reações transfusionais hemolíticas nos pacientes com anemia falciforme (PINTO, 2001). Sendo assim, o objetivo da presente pesquisa é relatar a importância da hemoterapia em pacientes falcêmicos, dando ênfase a importância dos concentrados de hemácias fenotipados para os pacientes falcêmicos.

\section{METODOLOGIA}

O trabalho foi desenvolvido com base em pesquisas bibliográficas de caráter qualitativo, descritivo e exploratório, onde foram utilizados como objetivo de estudo artigos científicos de base de dados virtuais: Scielo (Scientific Electronic Library Online), Google Acadêmico, PubMed. Foram utilizadas como descritores as seguintes palavras-chave: transfusão sanguínea; hemácias fenotipadas; e anemia falciforme. Em relação à pesquisa de periódicos científicos, foram selecionados artigos para a revisão de literatura. A pesquisa bibliográfica foi realizada entre os meses de junho a outubro de 2017.

\section{DICUSSÃO TEÓRICA}

\section{Hemoterapia em pacientes falcêmicos}

A hemoterapia consiste na transfusão dos componentes sanguíneos, que são os concentrados de hemácias, concentrados de plaquetas, plasma fresco congelado e crioprecipitado, contudo as mesmas ocorrem dependendo da necessidade do paciente, baseando-se em avaliação clínica e laboratorial, não havendo indicações de sangue total. As indicações básicas para transfusões são restaurar ou manter a capacidade de transporte de oxigênio, volume sanguíneo e a hemostasia (FERREIRA, 2007).

É muito importante para a hemoterapia a determinação correta do grupo $A B O$ e Rh (D), para evitar problemas relacionados às transfusões incompatíveis, e assim permitir o melhor uso dos hemocomponentes com fenótipos menos frequentes (MARTINS, 2009). No entanto, sabe-se que as transfusões sanguíneas é um evento irreversível, onde há benefícios e riscos potenciais aos receptores. Mesmo sendo feitas com indicação e administração precisas e corretas, não são isentas de complicações, onde se destacam as reações transfusionais, que são todas as intercorrências que ocorrem em consequência das transfusões de hemocomponentes, pois elas ocorrem durante ou após a transfusão, e podem ser classificadas como imediatas ou tardias ou imunológicas ou não imunológicas (FREITAS, 2014).

A imunofenotipagem eritrocitária previne umas das principais complicações da terapia transfucional nos pacientes portadores de anemia falciforme uma vez que a presença de aloanticorpos (anticorpos que reagem com um aloantígeno) e autoanticorpos (anticorpos produzidos pelo sistema imune que atua contra uma ou mais proteínas do próprio indivíduo que o produziu) dificulta a obtenção de sangue compatível e podem ocasionar reações transfusionais hemolíticas agudas ou tardias, aumentando a morbidade da doença (PINTO, 2001). 
A transfusão de concentrados de hemácias é comum na anemia falciforme, pois previne lesões orgânicas e aumenta a oxigenação, porém os pacientes estão sob o risco de muitas complicações que são: infecção transmitida pelo o sangue, aloimunização e reações alérgicas; por isto, os doadores devem ser compatíveis aos antígenos dos sistemas Rh, Kell, Kidd e Duffy (MARQUES, 2012).

A compatibilidade do sistema $A B O$ e o antígeno $D$ do sistema Rh é essencial na precaução de reações hemolíticas, e desejável que outros antígenos sejam compatibilizados, especialmente C, c, E, e do sistema Rh, assim como os principais antígenos dos sistemas Kell, Kidd, Duffy (MARTINS, 2009). A OMS define anemia como a condição quando a hemoglobina está abaixo dos valores normais para a idade, o sexo, o estado fisiológico e a altitude, sem considerar a causa da deficiência.

Em 1910, a anemia falciforme foi descrita por Herrick. Essa hemoglobinopatia é originária da África, disseminando-se pelo Brasil pela vinda dos escravos, sendo hoje a doença hereditária mais comum no país. Dentre as hemoglobinopatias, a anemia falciforme é a anemia que causa um processo hemolítico nas hemácias, que é resultante de fatores genéticos no que diz respeito ao gene da hemoglobina, que é a troca do ácido glutâmico por uma valina na posição 6 da cadeia beta da hemoglobina, essas transformações leva com que os eritrócitos forma formato de foice (MARQUES, 2012). As hemácias da anemia falciforme têm sobrevida muito curtas de 16 a 20 dias, menos que das células normais que são de 120 dias (FELIX, 2010).

A transfusão acarreta tanto benefícios, quanto riscos ao receptor. As reações transfusionais podem ser classificadas em reações imediatas (agudas) ou tardias. Uma das principais complicações é o desenvolvimento de aloanticorpos e autoanticorpos contra os eritrócitos. O perfil de antígenos eritrocitários em doadores e receptores é importante na prevenção de desenvolvimento dos anticorpos (GOMES, 2014).

Recomenda-se utilizar $\mathrm{CH}$ fenotipadas para os seguintes antígenos: - C,C,E,e (Sistema Rh), K, k (Sistema Kell), Fya, Fyab (Sistema Duffy), Jka, Jkb (Sistema Kidd), Dia (Sistema Diego), S,s (Sistema MNS): em portadores de anemia falciforme. A utilização de hemácias fenotipadas evita que os pacientes sejam aloimunizados contra antígenos eritrocitários. É indicado nos portadores de talassemia, de anemia falciforme em programa de transfusão regular, de anemia aplástica e de síndrome mielodisplásica.

\section{Sintomatologia da anemia falciforme}

A anemia falciforme ocasiona vários sintomas e complicações em seus portadores, portanto nos primeiros seis meses de vida os pacientes falcêmicos não apresentam sintomas, pois há presença de hemoglobina fetal $(\mathrm{HbF})$, que garante proteção contra fenômenos de falcização, pois a mesma tem maior afinidade pelo oxigênio. A partir desse período a produção de HbF é substituída pelas as cadeias beta, onde ocorre a estabilização na produção de globinas. Assim a hemoglobina HbS passa a ser produzida em quantidades maior, e o portador perde a propriedade protetora da HbF (FIGUEIREDO, 2014).

Portanto, os portadores de anemia falciforme passam a sentir sintomas após a troca da hemoglobina F pela $S$, pois as hemácias dos pacientes falcêmicos são menos flexíveis e tem vida média menor que das hemácias normais; essas impedem o fluxo sanguíneo, ocorrendo às manifestações clinicas mais frequentes: 
crise vaso oclusiva; infecções; Síndrome Torácica Aguda (STA); sequestro esplênico; priapismo; crise aplástica; Acidente Vascular Cerebral (AVC); úlceras; Síndrome mão-pé; e icterícia (BRUNETTA, 2010).

O sintoma mais comum é a crise vaso oclusiva, e para a grande maioria dos pacientes as complicações vaso oclusiva são mais problemáticas que a própria anemia, pois a mesma é bastante dolorida (FIGUEIREDO et al., 2014). A adesão das hemácias falcêmicas ao endotélio vascular dos capilares causa a crise vasooclusiva. Como as hemácias, plaquetas e leucócitos estão aderidos ao endotélio os fluxos sanguíneos são reduzidos causando o afoiçamento das hemácias. Os episódios de vaso-oclusão causarão lesões em tecidos, órgãos, ossos, articulações e vasos cerebrais (MARQUES, 2012).

As crises dolorosas geralmente são de início agudo, duram em média de 3 a 5 dias, podendo ocorrer pelo frio, desidratação, infecção ou consumo de álcool, porém a causa da maioria dos episódios não é definida (MARQUES, 2012). Os sintomas manifestados são: palidez muco-cutânea de instalação súbita, acompanhada de distensão e dor abdominal pela esplenomegalia, podendo ocorrer polidipsia, esses episódios variam de intensidade, podendo se resolver espontaneamente ou evoluir a óbito em horas. (MARQUES, 2012).

O acometimento clínico dos pacientes varia bastante, pois acontece dependendo do acometimento genético individual e com os hábitos dos mesmos em relação a profilaxia dos fatores predispostos às crises, como a desidratação, acidose, infecções, etc. (FIGUEIREDO, 2014). Desta forma, o conhecimento das intercorrências na doença falciforme é de extrema importância para todos os níveis de atendimento destes pacientes, já que a deteç̧ão precoce das complicações possibilita tratamento adequado e diminuição da morbimortalidade relacionada a elas (FIGUEIREDO, 2014).

\section{Diagnóstico da anemia falciforme}

O diagnóstico da anemia falciforme é complexo, pois envolve análise dos dados clínicos, herança genética e vários outros fatores como idade, ocasião da coleta, condições de armazenagem da amostra, entre outros. No entanto o diagnóstico pode ser realizado desde o recém-nascido (neonato) até o indivíduo adulto. O diagnóstico é divido em vários testes, como: o teste de triagem, este se utiliza para um pré-diagnóstico; o hemograma; os testes de solubilidade; dosagem de hemoglobina fetal e hemoglobina A2; focalização isoelétrica e imunoensaio. Mas a técnica mais qualificada para a confirmação do diagnóstico desta hemoglobinopatia é a eletroforese de hemoglobina em acetato de celulose ou em agarose, com pH variando de 8 a 9 (NOGUEIRA, 2013).

Portanto, a utilização da triagem neonatal para o diagnóstico é de fundamental importância. O teste mais utilizado é o 'teste do pezinho', que é eficaz e está sendo utilizado em quase todos os países. A triagem possibilita a instituição do tratamento preventivo, no sentido de diminuir a mortalidade infantil. Também está sendo incluída a eletroforese nos testes de triagem neonatal, até mesmo substituindo os métodos convencionais. A eletroforese tanto por focalização isoelétrica e/ou pela cromatografia liquida de alta resolução, pois constitui uma elevada precisão para o diagnóstico da anemia (FIGUEIREDO, 2014). 
Quando o portador de anemia falciforme está na fase adulta, está pode ser confirmada pela eletroforese em $\mathrm{pH}$ ácido, pois todas as hemoglobinopatias normais, $\mathrm{HbA}, \mathrm{HbA2}, \mathrm{HbF}$, e as anormais, $\mathrm{HbS}$ e outras, podem ser identificadas com êxito por meio da eletroforese em pH alcalino e ácido. Os testes com a pesquisa de drepanócitos, também podem ser capazes de diagnosticar, embora seja incapaz de diferenciar os vários tipos genótipos, mas confirma a presença de HbS. Até mesmo os exames de imagem, como: radiografia simples, ressonância magnética que acrescentam no diagnóstico, pois, estes expressam aspectos característicos da doença (FIGUEIREDO, 2014).

Quanto mais rápido o diagnóstico do indivíduo homozigoto, mais fácil será o encaminhamento para o médico específico, para que haja o tratamento precoce e as manifestações clinicas, que muitas das vezes são dolorosas e graves seja minimizada. A detecção precoce também facilitará o aconselhamento genético aos portadores do traço falciforme (FIGUEIREDO, 2014).

\section{Tratamento da anemia falciforme}

As doenças falciformes não há tratamentos específicos, mas as pessoas falcêmicas tem que ter um acompanhamento médico por toda a vida evitando as complicações mais graves da doença (MALU, 2013). Portanto, há tratamento paliativo para o paciente falcêmico que pode ser farmacológico e não farmacológico. Os analgésicos que são utilizados para o alivio das dores depende dos níveis de dor expresso pelo paciente (MALU, 2013).

Dentre as medidas simples para melhorar o quadro do doente estão: hidratação com 2 a 31 de água por dia, pois quando desidratado o paciente sofre crises de afoiçamento; devem ser evitados locais com pouco oxigênio, porque a hipóxia gera maior afoiçamento das hemácias; uma alimentação rica em ácido fólico e a sua suplementação são muito importantes, pois ajuda na eritropoiese que geralmente está deficiente nesses pacientes; porem alimentos ricos em ferro deve ser restritos devido à intensa hemólise das hemácias (GODFREY et al., 2010).

A principal forma de tratamento é a utilização da hemoterapia, pois a transfusão de concentrado de hemácias fenotipadas é aplicada na terapia transfucional para a prevenção e o tratamento das complicações das anemias falciformes; melhorando a capacidade de transporte de oxigênio e o fluxo de sangue na microcirculação pela diminuição na porcentagem de hemoglobina $S$ (HbS) e pelo aumento no nível de hematócrito, que não deverá exceder 30\%, o que previne eventos vaso-oclusivos clinicamente significantes. Portanto a transfusão é um dos pilares para a melhora dos pacientes (PINTO, 2001).

Devido as sensibilidades as transfusões sanguíneas podem causa reações imunológica sendo a aloimunização uma complicação comum entre os pacientes. Os estudos dos grupos sanguíneos em doadores de sangue proporcionam a comparação da frequência dos genes mais imunogênicos de cada sistema, sendo importante para diminuir o risco de aloimunização (PINTO, 2001).

A imunofenotipagem eritrocitária nos pacientes portadores de anemia falciforme é importante para prevenir uma das principais complicações da terapia transfusional, uma vez que a presença de aloanticorpos 
e autoanticorpos dificulta a obtenção de sangue compatível e pode ocasionar reações transfusionais hemolíticas agudas ou tardias, aumentando a morbidade da doença.

Dois estudos mostraram diferença na frequência dos antígenos entre doadores de sangue e pacientes SS detectados pela fenotipagem eritrocitária. No estudo de Moreira Junior et al. (1996), houve diferença significante na frequência do antígeno C, e na pesquisa de Matsuura (2004), na frequência dos antígenos D, Fy (a), Fy (b), S e s. A análise comparativa dos fenótipos eritrocitários entre os pacientes com doença falciforme e doadores de sangue detectou diferenças que não influenciaram na aloimunização eritrocitária, já que não foram detectados aloanticorpos contra os referidos antígenos. Portanto, esses dados permitem concluir que eles são semelhantes nos principais fenótipos de sistemas de grupos sanguíneos.

Os pacientes que receberam mais de dez transfusões de hemácias apresentaram chance 16 vezes maior de se aloimunizar, comparados a pacientes com menos transfusões. Detectou-se que $80 \%$ dos aloimunizados haviam recebido mais de dez unidades de hemácias, assim como no estudo de Fabron Jr. (2001), no qual a maioria dos pacientes aloimunizados (61,5\%) recebeu previamente mais de dez unidades de concentrado de hemácias. Segundo Moreira Junior et al. (1996), o risco calculado de aloimunização por unidade de $\mathrm{CH}$ transfundida em brasileiros com anemia falciforme é aproximadamente 1,15\%.

A fenotipagem eritrocitária dos pacientes e dos doadores mostrou diferença estatística para o Ag c, reforçando a importância do uso de sangue fenotipado para o sistema Rh. Também foi constatada diferença estatística dos antígenos s, Fy (b) e JK (b), que são menos imunogênicos que os do sistema Rh, o que reflete a importância da fenotipagem ampliada dos sistemas sanguíneos MNSs, Kidd e Duffy para prevenir a aloimunização nos pacientes com anemia falciforme, corroborando com Araújo et al. (2006), que recomendam expandir a pesquisa de antígenos eritrocitários ao indicar a transfusão de hemácias em pacientes politransfundidos (GODFREY et al., 2010).

Os resultados deste estudo são semelhantes aos obtidos na pesquisa realizada na Arábia Saudita com análise retrospectiva da história clínica e transfusional de 350 pacientes entre dois e 75 anos que receberam pelo menos uma transfusão. Tais autores identificaram aloimunização em $48(13,7 \%)$ pacientes e os aloanticorpos detectados foram: anti-E (18,8\%), não especificado (12,5\%), inconclusivo $(12,5 \%)$, anti-K $(10,4 \%)$ e anti-c $(6,3 \%)$ e maioria dos casos com múltiplos anticorpos. Concluímos, conforme Bashawri, que a prevalência de aloimunização e suas consequências são importantes para o manejo clínico e prática laboratorial de pacientes com anemia falciforme.

\section{CONCLUSÃO}

Conclui-se que a hemoterapia - transfusão de concentrado de hemácias fenotipadas - é a principal forma de tratamento da anemia falciforme, pois melhora a capacidade de transporte de oxigênio e o fluxo de sangue na microcirculação, pela diminuição na porcentagem de hemoglobina $\mathrm{S}(\mathrm{HbS})$ e pelo aumento no nível de hematócrito, o que previne eventos vaso-oclusivos clinicamente significantes. A complexidade e a 
gravidade das complicações clínicas da anemia falciforme dificultam o tratamento, e isso faz com que ela seja um desafio para a medicina e ciência.

A anemia falciforme até os dias de hoje é um desafio para seus portadores e profissionais da área, porque há uma grande dificuldade dos processos fisiopatológicos e por causa da gravidade de muitas das suas manifestações clinicas. Por isso é importante que a doença seja detectada precocemente. O profissional biomédico é um dos principais responsável por isso, pois é qualificado para realizar os exames clínicos, a fim de diagnosticar e esclarecer o real quadro clínico e o tratamento adequado para doença.

Para concluir, a fenotipagem eritrocitária dos doadores e pacientes mostrou a importância da identificação das diferenças dos fenótipos entre doadores e receptores, com objetivo de evitar a aloimunização, uma das principais complicações da terapêutica transfusional. A prevalência de aloimunização nos pacientes foi $12,7 \%$, sendo $70 \%$ dos anticorpos encontrados pertencentes a grupos sanguíneos Rh e Kell. Os fatores associados à aloimunização eritrocitária em pacientes portadores de anemia falciforme foram receber mais de dez transfusões de hemácias e maior tempo decorrido após a transfusão de hemácias.

Mesmo havendo formas de tratamento para doença, como a hemoterapia, a utilização de remédios, estes são apenas meios para diminuir os sintomas e o paciente ter melhor qualidade de vida, mas ainda não foi encontrada a cura. Destarte, é necessário maiores estudos e conhecimentos biológicos da doença, para que em um futuro próximo, possa oferecer possibilidades de cura.

\section{REFERÊNCIAS}

ARAÚJO, M. T. F.; MEDEIROS, S. D. V. M.; SOUZA, M. D. S. A.; BEZERRA, L. R. M.. Frequência da fenotipagem eritrocitária em pacientes politranfundidos. Revista Brasileira de Hematologia e Hemoterapia, v.28, n.4, p.334, 2006.

BRUNETTA, D. M.; CLÉ, D. V.; HAES, T. M.; RORIZ-FILHO J. S.; MORIGUTI, J. C.. Manejo das complicações agudas da doença falciforme. Revista Brasileira de Hematologia e Hemoterapia, v.43, n.3, p.231-237, 2010.

FABRON JUNIOR, A.. Estudo da significância clínica de aloanticorpos eritrocitários em pacientes com anemia falciforme. Revista Brasileira de Hematologia e Hemoterapia, v.21, p.121-122, 2001.

FELIX, A. A.; SOUZA, H. M.; RIBEIRO, S. B. F.. Aspectos epidemiológicos e sociais da doença falciforme. Revista Brasileira de Hematologia e Hemoterapia, v.32, n.3, p.203208, 2010.

FERRAZ, M. H. C.; MURÃO, M.. Diagnostico laboratorial da doença falciforme em neonatos e após sexto mês de vida. Revista Brasileira de Hematologia e Hemoterapia, v.29. n.3, p.218-222, 2007.

FERREIRA, O.; MARTINEZ, E. Z.; MOTA, C. A.; SILVA, A. M.. Avaliação do conhecimento sobre hemoterapia e segurança transfusional de profissionais de enfermagem. Revista Brasileira de Hematologia e Hemoterapia, v.29, n.2, p.160167, 2007.
FIGUEIREDO, A. K. B.; SANTOS, F. A. V.; SÁ, L. H. S.; SOUSA, N. D. L.. Anemia falciforme: abordagem diagnóstica laboratorial. Revista de Ciências da Saúde Nova Esperança, v.12, n.1, p.96-103, 2014.

FREITAS, J. V.; ALMEIDA, P. C.; GUEDES, M. V. C.. Perfil das reações transfusionais em pacientes pediátricas oncológico. Revista de Enfermagem da UFPE, v.8, n.9, p.3030-3038, 2014.

GODFREY, G. J.; LOCKWOOD, W.; KONG, M.; BERTOLONE, S.; RAY, A.. Antibody development inpediatric cell patients undergoing erythocytapheresis. Pediatric Blood \& Cancer, v.55, p.1134-1137, 2010.

GOMES, G. G.. Avaliação de aloimunização e autoimunização eritrocitária em crianças portadoras de anemia falciforme, indicadas ao regime de hipertranfusão por doppler transcraniano alterado ou acidente vascular encefálico instalado. Monografia (Graduação em Medicina) - Universidade Federal da Bahia, Bahia, 2014.

HELMAN, R.. Potenciais benefícios da genotipagem eritrocitária em larga escala como estratégia de prevenção de aloimunização em pacientes com doença falciforme. Dissertação (Mestrado em Medicina) - Faculdade de Ciências Médicas da Santa Casa de São Paulo, São Paulo, 2012. 
MALU, A. J.; CRISTINE, M. D.. Conhecendo e tratando as hemoglobinopatias: Anemia falciforme e beta-talassemia. FOCO: Caderno de Estudos e Pesquisas, v.4, n.5, p.41-60, 2013.

MARQUES, V.; SOUZA, R. A. A. R.; RAMOS L. J.; ZAN, R. A.; MENEGUETTI, D. V. O.. Revendo a anemia falciforme: sintomas, tratamento e perspectivas. Revista Científica da Faculdade de Educação e Meio Ambiente, v.3, n.1, p.39-61, 2012.

MARTINS, M. L.; CRUZ, K. V. D.; SILVA, M. C. F.; VIEIRA, Z. M. Uso da genotipagem de grupos sanguíneos na elucidação de casos inconclusivos na fenotipagem eritrocitária de pacientes atendidos na fundação Hemominas. Revista Brasileira de Hematologia e Hemoterapia, v.31, n.4, p.252259, 2009.

MATSUURA, M. M.. Imunização eritrocitária em pacientes com doença falciforme no estado do Amazonas.
Dissertação (Mestrado em Ciências Hematológicas) Universidade Federal de São Paulo, São Paulo, 2004.

MOREIRA JUNIOR, G.; BORDIN, J. O.; KURODA, A.; KERBAUY, J.. Red blood cell alloimmunization in sichle cell disease: the influence of racial and antigenic pattern differences between donors and recipients in Brazil. American Journal of Hematology, v.52, p.197-200, 1996.

NOGUEIRA, K. D. A.; SILVA, W. D. L; PAIVA, S. G.. Diagnostico laboratorial da anemia falciforme. Revista Científica do ITPAC, v.6, n.4, p.2-4, 2013.

OSÓRIO, M. M.. Fator de determinante da anemia em crianças. Jornal de Pediatria, v.78, n.4, p.269-278, 2002.

PINTO, P. C. A.; BRAGA, J. A. P.; SANTOS, A. M. N.. Fatores de risco para aloimunização em pacientes com anemia falciforme. Revista da Associação Médica Brasileira, v.57, n.6, p.668-673, 2001. 